\title{
PENGEMBANGAN KURIKULUM 2013 BERBASIS PENDIDIKAN MULTIKULTURAL
}

\author{
Printa Kusumastuti \\ Pascasarjana UIN Sunan Kalijaga
}

\begin{abstract}
Abstrak
Kurikulum 2013 yang mulai diterapkan di seluruh sekolah, baik negeri maupun swasta membutuhkan pendekatan baru dalam implementasinya. Pendidikan multikultural yang dewasa ini kerap diperbicangkan dirasa dapat dijadikan pendekatan dalam implementasi kurikulum tersebut. Mengingat, kekerasan yang melibatkan siswa masih saja ditemukan. Tak pelak fenomena tersebut mencederai iklim pendidikan negeri ini. Selain itu, bangsa Indonesia yang multikultur terdiri dari varian etnik, budaya, dan agama membutuhkan pijakan untuk menjaga harmoni dan integrasi dalam berbangsa dan negara.
\end{abstract}

\section{Kata Kunci}

Pendidikan multikultural, kurikulum 2013, harmoni, integrasi, siswa

\section{Pendahuluan}

Akhir-akhir ini sering kita jumpai kekerasan dalam dunia pendidikan kita. Kekerasan-kekerasan tersebut dalam bentuk verbal dan non verbal. Dalam hal ini yang sering menjadi korban kekerasan tersebut adalah peserta didik. Sebagai contoh kekerasan yang menimpa siswa SMAN 4 Wira Bangsa Meulaboh, Aceh ${ }^{1}$ dan SMAN 3 Jakarta. ${ }^{2}$ Kekerasan

1 Peristiwa terjadi di Sekolah Menegah Atas Negeri (SMAN) 4 Wira Bangsa Meulaboh, Aceh Barat. Kali ini menimpa siswa Ridha Firnanda (17) dianiaya kakak kelasnya, atau biasa disebut "senior". Peristiwa itu terjadi Minggu (24/10) dini hari di asrama sekolah unggul di Aceh Barat itu. Lihat Riza, "Siswa Wira Bangsa Dianiaya Senior," dalam, http://aceh.tribunnews.com/2015/10/27/siswa-wira-bangsa-dianiayasenior., Diakses tanggal 15 Januari 2016.

2 Kasus ini bermula dari cekcok yang terjadi antara enam siswa SMA 3 dan seorang pria bernama Erick, 30 tahun, 30 Januari 2015 lalu. Saat itu, ada siswi yang 
yang lebih fatal lagi menimpa siswa SMAN 7 Ternate ${ }^{3}$ hingga meninggal dunia. Diskriminasi tersebut menjadi ironi karena terjadi di sekolah.

Sekolah sebagai lembaga pendidikan seharusnya menjadi tempat belajar yang nyaman bagi siswa dan jauh dari tindak diskriminasi. Untuk itu sekolah sebagai lembaga pendidikan harus mereformasi sistem pendidikannya menjadi lebih baik. Kurikulum sebagai komponen terpenting dalam pendidikan harus menjadi pionir tegaknya prejudice. keadilan, dan HAM. Kurikulum sebagai suatu prinsip yang menggunakan keragaman kebudayaan peserta didik dalam mengembangkan filosofi, misi, tujuan, dan komponen kurikulum serta lingkungan belajar siswa sehingga siswa dapat menggunakan kebudayaan pribadinya untuk memahami dan mengembangkan berbagai wawasan, konsep, ketrampilan, nilai, sikap, dan moral yang diharapkan. Pendidikan multikultural memberikan secercah harapan dalam mengatasi berbagai gejolak masyarakat yang terjadi akhir-akhir ini, mengingat pendidikan multikultural adalah pendidikan yang senantiasa menjunjung tinggi nilainilai, keyakinan, heterogenitas, pluralitas dan keragaman. Dalam dimensi lain, pendidikan multikultural merupakan pengembangan kurikulum dalam aktivitas pendidikan untuk memasuki berbagai pandangan, sejarah, prestasi, dan perhatian terhadap orang-orang dari etnis lain.

mengaku mengalami pelecehan seksual. Rekan-rekannya hanya mengaku membantu dengan memukuli Erick. Lihat Ninis Chairunnisa, "Dari CCTV, Ada Bukti Baru Kasus Kekerasan SMA 3," dalam http://metro.tempo.co/read/news/2015/02/16/064642990/ dari-cctv-ada-bukti-baru-kasus-kekerasan-siswa-sma-3., diakses 5 Januari 2018.

${ }^{3}$ Kekerasan di dunia pendidikan yang mengundang kematian kembali terulang. Peristiwa kali ini, menimpa seorang siswa SMA di Kecamatan Pulau Moti, Kota Ternate, Provinsi Maluku Utara. Gara-gara tindakan FS alias Fajrin oknum guru honorer yang kelewatan. Yusri H Muhammad (17) siswa kelas XII, SMAN 7 Kota Ternate, harus kehilangan nyawa. Siswa malang itu, diduga tewas akibat dipukul Fajrin pakai benda keras di bagian belakang kepala. Yusri menghembuskan nafas sebelum sempat mencapai puskesmas terdekat. Lihat Hamadi, "Innalillah, Siswa SMA Tewas Dianiaya Pak Guru Pakai Penggaris", dalam http://www.jawapos.com/read/2015/10/10/6655/innalillahisiswa-sma-tewas-dihantam-penggaris-pak-guru/2., diakses 15 Januari 2018. 
Dalam tulisan ini akan dibahas tentang pengembangan kurikulum 2013 berbasis pendidikan multikultural.

\section{Pengembangan Kurikulum 2013 Berbasis Pendidikan Multikultural}

Kementerian Pendidikan dan Kebudayaan kini sedang gencar melakukan sosialisasi kurikulum 2013 yang dinilai memiliki muatan pembelajaran yang mampu mendorong siswa lebih kreatif. Kurikulum 2013 adalah kurikulum berbasis kompetensi yang pernah digagas dalam Rintisan Kurikulum Berbasis Kompetensi (KBK) 2004, tapi belum terselesaikan karena desakan untuk segera mengimplementasikan Kurikulum Tingkat Satuan Pendidikan (KTSP) 2006. ${ }^{4}$ Kurikulum 2013 sendiri merupakan sebuah kurikulum yang mengutamakan pada pemahaman, skill, dan pendidikan berkarakter, dimana siswa dituntut untuk paham atas materi, aktif dalam proses berdiskusi dan presentasi serta memiliki sopan santun dan sikap disiplin yang tinggi. Pada kurikulum 2013 istilah SK-KD (Standar Kompetensi-Kompetensi Dasar) diganti menjadi Kompetensi Inti dan Kompetensi Dasar. ${ }^{5}$

Implementasi kurikulum berbasis multikultural harus mengacu pada semangat multikulturalisme. Sejarah multikultural dimulai pada tahun 1950-an di Kanada. Menurut Longer Oxford dictionary istilah multikultural diambil dari istilah yang terdapat di surat kabar Kanada, Montreal Times yang menggambarkan masyarakat Montreal sebagai masyarakat "Multikultural dan Multilingual"6. Secara terminologi

\footnotetext{
4 Kemendikbud, “Implementasi Kurikulum 2013," dalam http://kemdikbud.go.id/ kemdikbud/artikel-mendikbud-kurikulum2013., Diakses tanggal 17 Oktober 2015.

5 Peraturan Menteri Pendidikan dan Kebudayaan Nomor 65 Tahun 2013 Tentang Standar Proses. hlm. 393.

6 Jeanne Ballantine, The Sociology of Education (London: Prentice Hall, 2000),
} 
multikultural berasal dari dua kata yaitu multi yang berarti banyak, kultural yang berarti budaya dan isme yang berarti aliran atau paham. Secara hakiki, dalam kata itu terkandung pengakuan akan martabat manusia yang hidup dalam komunitasnya dengan kebudayaannya masing-masing-masing yang unik. ${ }^{7}$ Dengan kata lain multikulturalisme adalah meyakini tentang adanya keberagaman yang ada di lingkungan sekitarnya.

Pendidikan Multikultural menurut James A. Bank dapat dilihat dari 3 (tiga) aspek: konsep, gerakan, dan proses. Dari aspek konsepnya, pendidikan multikultural dipahami sebagai ide yang memandang semua siswa-tanpa memperhatikan gender dan kelas sosial mereka, etnik mereka, ras mereka, dan atau karakteristik-karakteristik kultural lainnya-memiliki kesempatan yang sama untuk belajar di kelas. ${ }^{8}$ Dari aspek gerakannya, pendidikan multikultural adalah usaha untuk mengubah sekolah-sekolah dan institusi-institusi pendidikan sehingga siswa dari semua kelas sosial, gender, ras, dan kelompok-kelompok kultural memiliki kesempatan yang sama untuk belajar. Perubahan yang dilakukan tidak hanya terbatas pada kurikulum, tetapi juga aspek lain seperti metode, strategi, manajemen pembelajaran, dan lingkungan sekolah. ${ }^{9}$

Mengintegrasikan visi pendidikan multikultural ke dalam sistem pendidikan nasional Indonesia diharapkan dapat mempercepat terwujudnya masyarakat yang demokratis, bersatu dari berbagai

${ }^{7}$ Mahfud, Pendidikan Multikultural,... hlm. 75.

8 James A Banks, "Chapter 1: Multicultural Education: Historical Development, Dimensions, and Practice," Review of Research in Education 19, no. 1 (1993): 3-49.

9 Miftahur Rohman and Zulkipli Lessy, "Practicing Multicultural Education through Religiously Affiliated Schools and Its Implications for Social Change," Jurnal Pendidikan Islam 6, no. 1 (2017): 1-24. 
perbedaan yang dimiliki selama ini. ${ }^{10}$ Salah satu cara menerapkan pendidikan multikultural di sekolah adalah dengan pengembangan kurikulum.

\section{Pengembangan Matapelajaran dalam Kurikulum 2013.}

Pendidikan multikultural dapat diterapkan dalam pembelajaran disemua mata pelajaran dalam kurikulum 2013. Buku-buku teks penunjang pembelajaran dalam kurikulum 2013, dapat mengajarkan kepada anak-anak Indonesia bahwa Indonesia merupakan salah satu negara multikultural terbesar di dunia. Pasalnya di dalam buku-buku penunjang tersebut sedikitnya ada enam tokoh anak-anak yang mencerminkan keragaman agama dan etnis di Indonesia. Dan hal ini bertujuan agar anak-anak Indonesia sejak bangku sekolah terbiasa hidup dalam keragaman yang dimiliki bangsa Indonesia. ${ }^{11}$

Setiap guru mata pelajaran dapat mengintegrasikan pendidikan multikultural dalam mata pelajaran yang diampunya. ${ }^{12}$ Tidak ada salahnya, peserta didik diajak berdialog dan belajar menumbuhkan kepekaannya terhadap kasus kekerasan yang terjadi. Bagaimana respon dan sikap peserta didik terhadap aksi-aksikekerasan yang terjadi bisa dijadikan sebagai masukan berharga dalam proses pembelajaran berbasis pendidikan multikultural. Guru perlu memberikan kebebasan kepada subjek didik untuk merespon dan menyikapinya, sehingga mereka merasa dihargai dan diperlakukan sebagai sosok yang amat dibutuhkan

10 Iwan Supardi and Sumarno Sumarno, "MODEL PENDIDIKAN MULTIKULTURAL RAMAH DI SEKOLAH ETHNO-RELIGIO SEGREGATION (E-RS) KOTA PONTIANAK," Jurnal Penelitian Dan Evaluasi Pendidikan 18, no. 2 (2014): 202-14.

${ }^{11}$ Menteri Pendidikan dan Kebudayaan Mohammad Nuh dalam acara sosialisasi Kurikulum 2013 kepada sekitar 500 guru, kepala sekolah, pengawas, dan dinas pendidikan kota/kabupaten di Pontianak, Minggu (10/3/2013).

${ }_{12}$ Miftahur Rohman and Mukhibat Mukhibat, "Internalisasi Nilai-Nilai SosioKultural Berbasis Etno-Religi Di MAN Yogyakarta III," Edukasia: Jurnal Penelitian Pendidikan Islam 12, no. 1 (February 1, 2017): 31-56, https://doi.org/10.21043/edukasia.v12i1.1771. 
kehadirannya dalam proses pembelajaran. Jangan sampai ada ketersinggungan sekecil apapun karena kecerobohan ungkapan guru. Sekecil apapun singgungan tentang agama akan membekas dalam benak siswa yang akan dibawa sampai dewasa.

\section{Pengembangan dalam kegiatan di luar jam pelajaran (pengembangan diri)}

Pengembangan dalam kegiatan di luar jam sekolah ini diadopsi berdasarkan model kurikulum REACH (Rural Educations and Cultural Heritage) dari Howard. Kurikulum REACH terdiri dari empat fase yang dapat dilakukan untuk membangun sensitifis dan kerjasama antaretnis yaitu: ${ }^{13}$

a. Membangun hubungan antar manusia atau antar etnis dapat dilakukan dengan berbagai kegiatan praktis. Dalam kurikulum 2013 kegiatan ini dapat dilakukan dengan kegiatan pengembangan diri seperti kegiatan perlombaan olahraga yang dapat diikuti oleh peserta didik karena dalam kegiatan olahraga tersebut pelaksanaannya melibatkan suasana yang menjalin hubungan social. Selain dalam kegiatan olahraga, pendidikan multikultural juga dapat dikembangkan dalam kegitan kepramukaan dimana kegiatan pramuka ini menjadi kegiatan pengembangan diri dalam kurikulum 2013 yang wajib diikuti oleh semua peserta didik.

b. Membangun kesadaran akan kelemahan dan kekuatan etnis sendiri, menumbuhkan rasa senang sebagai anggota kelompok etnis masing-masing. Dalam kurikulum 2013 kegiatan ini dapat dikembangkan melalui pendidikan berbasis keunggulan lokal adalah pendidikan yang memanfaatkan keunggulan lokal dalam aspek ekonomi, budaya, bahasa, teknologi, ekologi dan lain-lain,

${ }_{13}$ Supardi, Model Pendidikan... hlm.127-128. 
yang bermanfaat bagi pengembangan kompetensi peserta didik agar mampu bersaing di tingkat lokal, nasional dan internasional. Pendidikan berbasis keunggulan lokal dapat merupakan bagian dari semua mata pelajaran dan juga dapat menjadi mata pelajaran Seni Budaya dan Prakarya. Contohnya untuk wilayah Yogyakarta terdapat mata pelajaran bahasa Jawa yang terintegrasi dalam Mata Pelajaran Seni Budaya, dan mata pelajaran Batik yang merupakan salah satu isi dari Mata Pelajaran Prakarya.

c. Membangun pemahaman terhadap budaya lain, sambil mengeksploitasi budaya sendiri. Kegiatan ini dapat dilakukan dalam kegiatan sekolah seperti kegiatan Penyembelihan Hewan Qurban di sekolah atau kegiatan Syawalan yang dilakukan oleh semua warga sekolah tanpa memandang agama yang dianut, semua warga sekolah dapat ikut berpartisipasi dalam kegiatan tersebut. Kegiatan ini dapat membangun sensitifitas dan kerjasama antar etnis/agama lain.

d. Pengalaman lintas budaya dimana peserta didik diberi kesempatan untuk melakukan kontak dan berinteraksi langsung dengan masyarakat yang berbeda etnis, dan budaya. Kegiatan ini biasanya dilakukan oleh sekolah dalam kegiatan studi wisata. Dalam rangka penanaman pendidikan multikultural, sebaiknya kegiatan studi wisata dilakukan untuk mengunjungi tempattempat yang mempunyai perbedaan etnis dan budaya dengan peserta didik. 


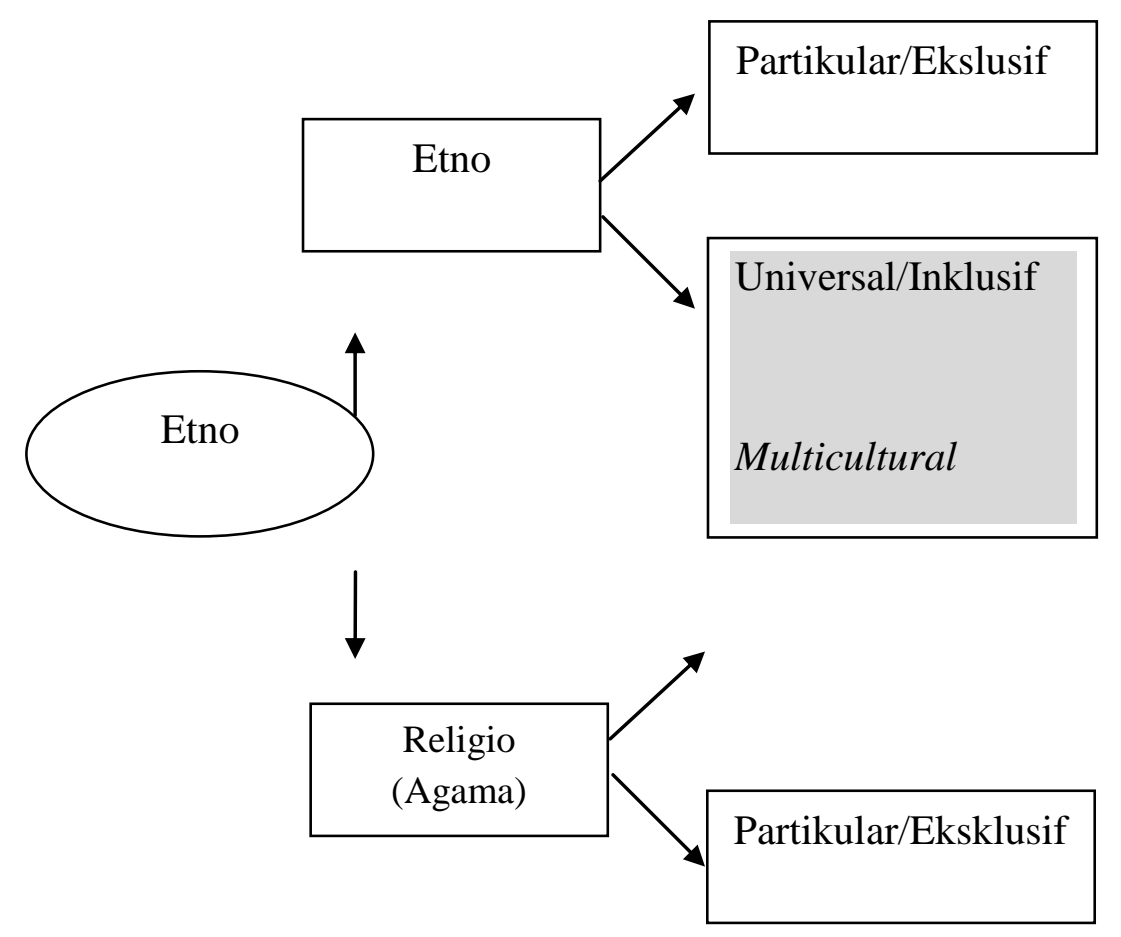

Gambar: Wilayah Potensial Pengembangan Pendidikan Multikultural. ${ }^{14}$

\section{Kesimpulan}

Pengembangan kurikulum 2013 berbasis pendidikan multikultural diharapkan membantu siswa mengerti, menerima dan menghargai orang lain yang berbeda suku, budaya dan nilai kepribadian. Lewat penanaman semangat multikulturalisme di sekolah, akan menjadi medium pelatihan dan penyadaran bagi generasi muda untuk menerima perbedaan budaya, agama, ras, etnis dan kebutuhan di antara sesama dan mau hidup bersama secara damai. Agar proses ini berjalan sesuai harapan, maka seyogyanya kita mau menerima jika pendidikan multikultural disosialisasikan dan didiseminasikan melalui lembaga pendidikan, serta,

14 Iwan Supardi, Sumarno, "Model Pendidikan Multikultural RAMAH di Sekolah Ethno-Religio Segregation (E-RS) Kota Pontianak", JURNAL EVALUASI PENDIDIKAN: Jurnal Penelitian dan Evaluasi Pendidikan, Progam Pascasarjana Universitas Negeri Yogyakarta., No. 2, Th. XVIII, Juni-Desember 2014, hlm. 202-203 
ditetapkan sebagai bagian dari kurikulum pendidikan di berbagai jenjang baik di lembaga pendidikan pemerintah maupun swasta.

Apalagiparadigma multikultural secara implisit juga menjadi salah satu concern dari Pasal 4 UU N0. 20 Tahun 2003 Sistem Pendidikan Nasional. Dalam pasal itu dijelaskan, bahwa pendidikan diselenggarakan secara demokratis, tidak diskriminatif dengan menjunjung tinggi HAM, nilai keagamaan, nilai kultural dan kemajemukan bangsa. ${ }^{15}$ Salah satu tujuan penting dari konsep pendidikan multikultural adalah untuk membantu semua siswa agar memperoleh pengetahuan, sikap dan ketrampilan yang diperlukan dalam menjalankan peran-peran seefektif mungkin pada masyarakat demokrasi-pluralistik serta diperlukan untuk berinteraksi, negosiasi, dan komunikasi dengan warga dari kelompok beragam agar tercipta sebuah tatanan masyarakat bermoral yang berjalan untuk kebaikan bersama.

Beberapa aspek yang menjadi kunci dalam melaksanakan pendidikan multikultural dalam struktur sekolah adalah tidak adanya kebijakan yang menghambat toleransi, termasuk tidak adanya penghinaan terhadap ras, etnis dan jenis kelamin. Juga, harus menumbuhkan kepekaan terhadap perbedaan budaya, di antaranya mencakup pakaian, musik dan makanan kesukaan. Selain itu, juga memberikan kebebasan bagi anak dalam merayakan hari-hari besar umat beragama serta memperkokoh sikap anak agar merasa butuh terlibat dalam pengambilan keputusan secara demokratis

15 Undang-undang Nomor 20 Tahun 2003 tentang Sistem Pendidikan Nasional pasal 4. 


\section{Daftar Pustaka}

Banks, James A. "Chapter 1: Multicultural Education: Historical Development, Dimensions, and Practice." Review of Research in Education 19, no. 1 (1993): 3-49.

Hamadi. "Innalillah, Siswa SMA Tewas Dianiaya Pak Guru Pakai Penggaris." Accessed January 10, 2018. http://www.jawapos.com/read/2015/10/10/6655/innalillahisiswa-sma-tewas-dihantam-penggaris-pak-guru/ 2 .

Jeanne, Ballantine, The Sociology of Education. London: Prentice Hall, 2010.

Kemendikbud. "Implementasi Kurikulum 2013," n.d. http://kemdikbud.go.id/kemdikbud/artikel-mendikbudkurikulum2013.

Mahfud, Choirul, Pendidikan Multikultural, Yogyakarta: Pustaka Pelajar, 2009.

Ninis Chairunnisa. "Dari CCTV, Ada Bukti Baru Kasus Kekerasan SMA 3." Accessed January 10, 2018. http:/ / metro.tempo.co/read/news/2015/02/16/064642990/ daricctv-ada-bukti-baru-kasus-kekerasan-siswa-sma-3.

Riza. "Siswa Wira Bangsa Dianiaya Senior." Accessed January 15, 2018. http://aceh.tribunnews.com/2015/10/27/siswa-wira-bangsadianiaya-senior.

Peraturan Menteri Pendidikan dan Kebudayaan Nomor 65 Tahun 2013 Tentang Standar Proses

Rohman, Miftahur, and Zulkipli Lessy. "Practicing Multicultural Education through Religiously Affiliated Schools and Its Implications for Social Change." Jurnal Pendidikan Islam 6, no. 1 (2017): 1-24.

Rohman, Miftahur, and Mukhibat Mukhibat. "Internalisasi Nilai-Nilai Sosio-Kultural Berbasis Etno-Religi Di MAN Yogyakarta III." Edukasia : Jurnal Penelitian Pendidikan Islam 12, no. 1 (February 1, 2017): 31-56. https:// doi.org/10.21043/edukasia.v12i1.1771.

Supardi, Iwan, and Sumarno Sumarno. "MODEL PENDIDIKAN MULTIKULTURAL RAMAH DI SEKOLAH ETHNO-RELIGIO SEGREGATION (E-RS) KOTA PONTIANAK." Jurnal Penelitian Dan Evaluasi Pendidikan 18, no. 2 (2014): 202-14.

Undang-undang Nomor 20 Tahun 2003 tentang Sistem Pendidikan Nasional. 